\title{
(6) OPEN ACCESS \\ A comparison of pain assessment by physicians, parents and children in an outpatient setting
}

\author{
Christina Brudvik, ${ }^{1,2}$ Svein-Denis Moutte, ${ }^{1,3}$ Valborg Baste, ${ }^{4}$ Tone Morken $^{3}$
}

\begin{abstract}
'Bergen Accident and Emergency Department, Bergen, Norway

${ }^{2}$ Department of Clinical

Medicine, University of Bergen,

Bergen, Norway

${ }^{3}$ National Centre for Emergency

Primary Health Care, Uni

Research Health, Bergen,

Norway

${ }^{4}$ Uni Research Health, Bergen,

Norway
\end{abstract}

\section{Correspondence to}

Dr Christina Brudvik, Bergen

Accident and Emergency

Department, Solheimsveien 9,

Bergen 5008, Norway;

christina.brudvik@uib.no

Received 25 February 2016

Revised 29 September 2016

Accepted 30 September 2016

Published Online First

25 October 2016
CrossMark

To cite: Brudvik C,

Moutte S-D, Baste V,

et al. Emerg Med J

2017;34:138-144

\section{ABSTRACT}

Introduction Our objective was to compare pain assessments by patients, parents and physicians in children with different medical conditions, and analyse how this affected the physicians' administration of pain relief.

Patients and methods This cross-sectional study involved 243 children aged 3-15 years treated at Bergen Accident and Emergency Department (ED) in 2011. The child patient's pain intensity was measured using ageadapted scales while parents and physicians did independent numeric rating scale (NRS) assessments.

Results Physicians assessed the child's mean pain to be NRS=3.2 (SD 2.0), parents: NRS=4.8 (SD 2.2) and children: NRS=5.5 (SD 2.4). The overall child-parent agreement was moderate (Cohen's weighted $\kappa=0.55$ ), but low between child-physician $(\kappa=0.12)$ and parentphysician $(\kappa=0.17)$. Physicians significantly

underestimated pain in all paediatric patients $\geq 3$ years old and in all categories of medical conditions. However, the difference in pain assessment between child and physician was significantly lower for fractures $(N R S=1.2$; $95 \% \mathrm{Cl} 0.5$ to 2.0 ) compared to wounds (NRS=3.4; $\mathrm{Cl}$ 2.2 to $4.5 ; p=0.001$ ), infections (NRS=3.1; $\mathrm{Cl} 2.2$ to $4.0 ; p=0.002$ ) and soft tissue injuries (NRS=2.4; $\mathrm{Cl} 1.9$ to $2.9 ; p=0.007$ ). The physicians' pain assessment improved with increasing levels of pain, but only $42.1 \%$ of children with severe pain (NRS $\geq 7$ ) received pain relief. Conclusions Paediatric pain was significantly underestimated by ED physicians. In the absence of a self-report from the child, parents' evaluation should be listened to. Despite improved pain assessments in children with fractures and when pain was perceived to be severe, it is worrying that barely half of the children with severe pain received analgesics in the ED.

\section{INTRODUCTION}

Children with pain are common patients in out-of-hours settings. ${ }^{1}$ The different qualitative and quantitative characteristics of the pain are important to analyse to identify various infections as well as different wounds or fractures. ${ }^{12}$ However, all patients should have adequate evaluation and treatment of the pain itself as well as the pain-inducing condition. ${ }^{3-5}$ Inadequate pain management during medical care can cause short-term problems like slower healing and long-term problems like anxiety, hyperaesthesia, needle phobia and fear of medical care. $^{67}$

Still, children are particularly susceptible to suboptimal pain management (oligoanalgesia) at all levels of healthcare, particularly in the acute outpatient setting. ${ }^{8}{ }^{9}$ Analgesia is used too

\section{Key messages}

What is already known on this subject?

- Children often receive less pain relief than adults for the same type of illness and injury in the outpatient and Emergency Department (ED) setting.

- In order to identify factors that affect the clinical handling of paediatric pain, we need more knowledge about how parents and physicians assess children's pain.

\section{What this study adds?}

- ED physicians significantly underestimate pain from all medical conditions in paediatric patients $\geq 3$ years old, especially from wounds, infections and soft tissue injuries, but less from fractures.

- Physicians' pain assessments improve with increasing levels of pain, but still, hardly half of the children with severe pain receive pain relief.

- Physicians should be cognizant that they are likely to underestimate children's pain; children's self-reports through age-appropriate pain scales and parents' assessments are important in order to improve pain management in the ED.

infrequently, often delayed in its administration and dosed too low. ${ }^{8}$ In a US study, pain relief was frequently not part of the EDs' treatment for fractures in children, even when pain was moderate or severe. ${ }^{9}$

It is important to identify why pain is not systematically addressed and insufficiently managed in the EDs. Time constraints and fear of reduced productivity and efficiency ${ }^{4}$ are possible factors, as well as physicians' reluctance to administer potent painkillers to children, with potential medical side effects. ${ }^{9}$ Previous studies of children with different neurological conditions and various age groups have revealed differences in pain assessments between health professionals, parents and child patients. $^{10-12}$

Our aims were (1) to investigate the level of agreement in children's pain intensity when assessed by the children, parents and physicians at a large Norwegian casualty centre, (2) to estimate the differences in pain intensity given by the children, parents and physicians by the age of children, medical condition and severity of pain and (3) to see how the pain assessments affected the ED physicians' administration of pain relief. 


\section{MATERIAL AND METHOD}

\section{Design and setting}

The study involves a subgroup of 243 children from a larger cross-sectional questionnaire survey of paediatric pain assessment at Bergen Accident and ED. This combined emergency primary care centre and ED gives treatment to patients in Bergen and its surroundings, with an annual number of 100000 consultations, including 19000 children and adolescents under the age of 20. Children attend the ED for different medical conditions including infections, different injuries and other pain-inducing medical conditions. Pain scoring is not mandatory in our ED, and ahead of the study, only $23 \%$ of the participating physicians had some experience in assessing pain in children aged 3-8 years, and 69\% in assessing pain in children aged 9 years and older. ${ }^{13}$ For this reason, and ahead of study start, both physicians and nurses were thoroughly informed about the numeric rating scale (NRS) and how to use it. They were also instructed in how to guide children in the use of age-appropriate pain scales.

\section{Data collection}

During 17 days in November 2011, all patients under 20 years of age, their parents and consulting doctors at Bergen ED were invited to participate in this survey. Follow-up patients were excluded. A nurse informed the patients and/or parents about the study upon arrival at the ED, and gave a brief instruction on how to use age-adapted pain scales. The questionnaire also had a detailed written description of how the parents should instruct the youngest children to interpret the different faces in the pain-scoring scales. Moreover, one of our authors was available for advice to healthcare workers and patients at any time during the study period.

The children and/or their parents provided written consent to the participation before they received a questionnaire to fill out ahead of the consultation. In addition to questions about the pain associated with the presenting problem, the child/parent and physician questionnaires provided demographic data like age, gender and nationality. The physicians' questionnaires also asked about medical experience in years, medical specialty and if they had children of their own. The child's diagnosis was registered and classified into one of the four diagnostic categories: infections, fractures, wound injuries or soft tissue, ligament or muscle injuries. The parents reported whether the child had received painkillers ahead of the consultation, and the physicians reported if pain relief was given during the consultation. Waiting time from ED arrival to consultation was registered.

\section{Participants}

Our main intention was to compare the degree of conformity in children's pain intensity when assessed by the child, parent and physician. In order to do the necessary matched-pair analysis of pain estimates, we excluded adolescents of 16 years of age and older as they often visited the ED without their parents. Likewise, we excluded children under 3 years, as most of them were unable to do a true child self-measurement of pain level.

The sample size was initially calculated for a study with a wider age span. Based on 243 children in the age group of 3-15 years, a difference in NRS from 4.0 to 5.0 with $\mathrm{SD}=2.5$ could be detected with a power of $87 \%$ in a two-sided test with a significance level of 0.05 .

We primarily invited 395 children aged 3-15 years, but 152 did not want to participate. Finally, we had data from 243 children (62\%), answers from their parents and evaluations from 51 different consulting physicians (figure 1).

\section{Measurements}

The questionnaires included age-appropriate pain scales. Children aged 3-8 filled out the Faces Pain Scale-Revised (FPS-R) and Wong Baker Faces Pain Rating scale, with six faces illustrating increasing levels of pain $(0-10)$, zero meaning no pain illustrated as a happy or neutral facial expression. ${ }^{14}$ Children aged 9-15 years used the Visual Analogue Scale (VAS) and the Coloured Analogue Scale (CAS) to illustrate pain severity along a continuous line from 0 to $100 \mathrm{~mm}$ between no pain (green colour) and the worst thinkable pain (red colour). ${ }^{14}$ Parents and the consulting doctors used NRS to estimate the child's level of pain from 0 to $10 .^{14} 15$ Parents made their pain assessment prior to the child, but they were not completely blinded to each other's answers. However, both parents and children were told not to inform the physicians about their

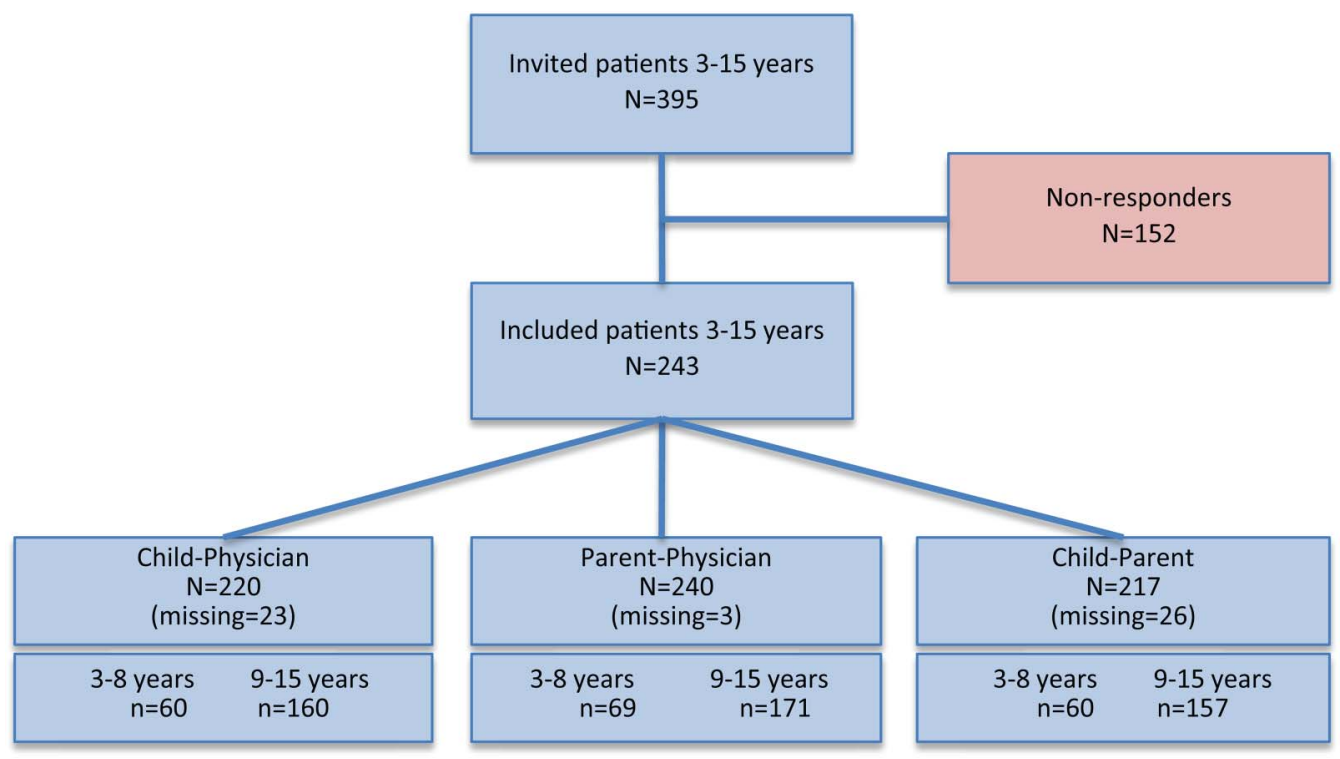

Figure 1 A flow chart showing the number of included, non-responders and missing patients, and age distribution. 
estimated pain scores. During the consultation, the physicians rated the paediatric pain in a separate questionnaire and assessed whether they thought the child's pain reaction was in concordance with the medical condition.

\section{Data analysis and statistics}

Descriptive statistics for the study population were derived from mean values and SD for continuous variables, median and interquartile range (IRQ) for waiting time (not normally distributed) and numbers and percentages for categorical variables. We calculated the mean pain intensity with SD, provided by the children, parents and doctors. The mean differences in pain intensity between age groups, diagnoses, doctors' perceived concordance between medical condition and pain, and painkillers given by parents or physicians were tested by one-way analyses of variance. The differences in parents' handling of pain relief before consultation, and physicians' administration of pain relief between age groups and diagnoses were tested by $\chi^{2}$ and Fisher's exact test. The outcome variables were visually assessed by histograms and found satisfactory regarding skewness and kurtosis. The only exception was the differences in mean pain intensity assessment in child-parent, where $40 \%$ had the value zero.

To assess the agreement in pain estimation between childphysician, parent-physician and child-parent, we calculated the percentage of accurate agreement and Cohen's linear weighted $\kappa$, which takes into account the magnitude of the discrepancy. To calculate $95 \%$ CI for the $\kappa$ values, 1000 bootstrap samples were generated. Based on the guidelines for interpreting $\kappa$, the following criteria were applied: $<0.20$ low; $0.21-0.40$ fair; $0.41-0.60$ moderate; $0.61-0.80$ good; and $0.81-1.0$ very good. ${ }^{16}$

The differences in pain assessment between the child and physician, and the parent and physician were estimated in a mixed effect model, with the physician included as a random intercept to account for intra-individual correlation. The differences in pain assessment between the child and parent were analysed in a generalised linear model. The selection of potential covariates (painkillers taken before consultation, waiting time, the child's gender, and the physician's gender, experience and country of birth) was based on a univariate analysis and $\mathrm{p}$ value $<0.05$ entailed inclusion in the models. Mixed effect models with physician as the random intercept were used to test the disparities between the following pairs: differences in child-physician pain assessment versus parent-physician, parent-physician versus child-parent and child-physician versus child-parent.

To investigate the physicians' administration of pain relief with regard to the estimated pain level in the children, physicians' pain assessment was divided into: mild pain (NRS $\leq 3$ ), moderate pain (NRS $=4-6$ ) and serious pain (NRS $\geq 7$ ). These pain levels were also used to evaluate concordance in assessment between the child and physician.

The statistical analyses were performed using STATA IC V.13. The level of statistical significance was set at 5\% $(\mathrm{p}<0.05)$.

\section{RESULTS}

\section{Descriptive data}

We included 243 children aged 3-15 years with a mean age of 10.6 years and 53\% boys. Most children (51\%) had soft tissue, ligament or muscle injuries, followed by fractures, different infections and wound injuries (table 1). The oldest children had more fractures $(28 \%)$ than the youngest $(13 \%)$, and the youngest children had more wounds (26\%) than the oldest (4\%) (table 1). The median waiting time between ED attendance and the consultation was $50 \mathrm{~min}(\mathrm{IQR}=55)$.
Table 1 Characteristics of the study population

\begin{tabular}{|c|c|c|c|}
\hline \multirow[b]{2}{*}{ Characteristics } & \multicolumn{3}{|c|}{ Age (years) } \\
\hline & $\begin{array}{l}3-8 \\
(n=69)\end{array}$ & $\begin{array}{l}9-15 \\
(n=174)\end{array}$ & $\begin{array}{l}\text { Total } \\
(\mathrm{N}=243)\end{array}$ \\
\hline Age in years, mean (SD) & $5.9(1.8)$ & $12.4(1.8)$ & $10.6(3.5)$ \\
\hline \multirow[t]{2}{*}{ Waiting time in minutes, mean (SD) } & $62(56)$ & $63^{*}(45)$ & $63.0(48)$ \\
\hline & n (\%) & n (\%) & n (\%) \\
\hline \multicolumn{4}{|l|}{ Diagnosis } \\
\hline Infection & $18(26.1)$ & $20(11.5)$ & 38 (15.6) \\
\hline Wound & $18(26.1)$ & $7(4.0)$ & $25(10.3)$ \\
\hline Fracture & $9(13.0)$ & $48(27.6)$ & $57(23.5)$ \\
\hline Soft tissue, ligament or muscle injury & $24(34.8)$ & $99(56.9)$ & $123(50.6)$ \\
\hline \multicolumn{4}{|c|}{ Concordance between medical condition and paint } \\
\hline Low & $7(10.1)$ & $16(9.2)$ & $23(9.5)$ \\
\hline Some & $24(34.8)$ & $57(32.8)$ & $81(33.3)$ \\
\hline High & $38(55.1)$ & $101(58.0)$ & $139(57.2)$ \\
\hline \multicolumn{4}{|l|}{ Painkiller } \\
\hline Parent $\ddagger$ & $13(18.8)$ & $21 \S(12.1)$ & $34(14.0)$ \\
\hline Physicianף & $5(7.2)$ & $16 \S(9.2)$ & $21(8.6)$ \\
\hline
\end{tabular}

The physicians' mean age was 36 years; 57\% were men, 51\% had children of their own and $77 \%$ were born in Norway. Half of them had more than 5 years of medical experience, and 30\% had a specialty in family medicine, but none in paediatrics. Emergency medicine is not a specialty in Norway.

\section{Mean pain assessments}

The doctors assessed the child's mean pain to be NRS $=3.2$. The parents' evaluation was higher $(\mathrm{NRS}=4.8)$ and the children's own evaluation was NRS=5.5 (table 2). Although children in the young and old age groups had almost similar mean pain intensity ratings, parents and physicians assessed the mean pain intensity to be lower in the youngest age group of children. The pain scores also differed between the diagnostic groups. Children themselves, as well as parents and physicians, estimated the highest mean pain intensity score when the child had a fracture (table 2). Only three patients had no pain according to the child's, parents' and physicians' evaluation.

\section{Agreement}

The proportion of agreement in pain intensity assessment between the children and physicians was $14.6 \%$, and the weighted $\kappa$ was 0.12 (95\% CI 0.07 to 0.19 ), which is considered low (figure 2A). The parent-physician agreement was also low, with a $15.0 \%$ agreement and weighted $\kappa$ of 0.17 (95\% CI 0.12 to 0.25 ) (figure $2 \mathrm{~B}$ ). The child-parent agreement was $40.1 \%$ and the weighted $\kappa$ was moderate, 0.55 (95\% CI 0.47 to 0.62) (figure 2C).

\section{Differences in pain intensity ratings}

Adjustments and influence of different factors

Parents provided painkillers to $14 \%$ of the children ahead of the consultation (table 1). The physicians estimated the mean pain intensity in these children to be $\mathrm{NRS}=3.2$, while parents and children assessed it to be $\mathrm{NRS}=5.6$ and 6.5 , respectively 
Table 2 Mean pain intensity assessed by children, parents and physicians by children's age, diagnosis, physicians' perceived concordance between medical condition and pain, painkillers taken before consultation and painkillers administered by the physician during consultation $(\mathrm{N}=243)$

\begin{tabular}{|c|c|c|c|c|c|c|c|c|c|}
\hline \multirow[b]{2}{*}{ Characteristics } & \multicolumn{3}{|c|}{$\begin{array}{l}\text { Children's assessment of } \\
\text { pain intensity }\end{array}$} & \multicolumn{3}{|c|}{$\begin{array}{l}\text { Parents' assessment of } \\
\text { pain intensity }\end{array}$} & \multicolumn{3}{|c|}{$\begin{array}{l}\text { Physicians' assessment of } \\
\text { pain intensity }\end{array}$} \\
\hline & Mean & SD & p Value* & Mean & SD & p Valuet & Mean & SD & p Value \\
\hline Total & 5.5 & 2.4 & & 4.8 & 2.2 & & 3.2 & 2.0 & \\
\hline Age (years) & & & 0.609 & & & $<0.001$ & & & $<0.001$ \\
\hline $3-8$ & 5.4 & 3.1 & & 4.0 & 2.4 & & 2.2 & 1.5 & \\
\hline $9-15$ & 5.5 & 2.1 & & 5.1 & 2.1 & & 3.6 & 2.0 & \\
\hline Diagnosis & & & 0.387 & & & 0.002 & & & $<0.001$ \\
\hline Infection & 5.4 & 3.0 & & 4.2 & 2.8 & & 1.9 & 2.3 & \\
\hline Wound & 4.7 & 2.9 & & 3.6 & 2.3 & & 1.8 & 1.0 & \\
\hline Fracture & 5.8 & 2.1 & & 5.3 & 1.6 & & 4.5 & 1.9 & \\
\hline Soft tissue, ligament or muscle injury & 5.5 & 2.2 & & 5.0 & 2.1 & & 3.3 & 1.6 & \\
\hline \multicolumn{2}{|c|}{ Concordance between medical condition and pain } & & 0.819 & & & 0.718 & & & 0.055 \\
\hline Low & 5.7 & 2.5 & & 5.1 & 2.8 & & 2.5 & 1.9 & \\
\hline Some & 5.6 & 2.3 & & 4.8 & 2.1 & & 3.0 & 1.7 & \\
\hline High & 5.4 & 2.5 & & 4.7 & 2.2 & & 3.4 & 2.1 & \\
\hline Painkillers by parent & & & 0.010 & & & 0.024 & & & 0.968 \\
\hline Yes & 6.5 & 2.0 & & 5.6 & 2.0 & & 3.2 & 1.9 & \\
\hline No & 5.3 & 2.4 & & 4.7 & 2.2 & & 3.2 & 2.0 & \\
\hline Painkillers by physician & & & 0.004 & & & 0.141 & & & $<0.001$ \\
\hline Yes & 7.0 & 2.2 & & 5.5 & 2.7 & & 5.0 & 2.4 & \\
\hline No & 5.3 & 2.4 & & 4.7 & 2.2 & & 3.0 & 1.8 & \\
\hline
\end{tabular}

(table 2). The average NRS difference between child and physician was 3.8 (95\% CI 2.3 to 4.2) among children who received painkillers and NRS $=2.2$ (95\% CI 1.7 to 2.6$)$ among those who did not $(p=0.031)$. A significantly higher proportion of children with infections compared with children with other diagnoses $(p=0.007)$ received painkillers from their parents. We adjusted for received painkillers in our further analysis (table 3). The mean waiting time between attendances at ED was not associated with differences in pain assessments, nor were the child's gender, the physician's gender, whether the physicians had children of their own, medical experience in years $(<5$ vs $\geq 5$ years), or the physician's country of birth.

\section{General differences}

In general, physicians assessed the child's mean pain level to be $\mathrm{NRS}=2.3(95 \%$ CI 1.9 to 2.8$)$ lower than the child's own assessment, and NRS $=1.6$ (95\% CI 1.3 to 2.0$)$ lower than the parents' estimation. Parents assessed the mean pain level to be 0.7 (95\% CI 0.4 to 0.9 ) lower than the child (table 3 ).

\section{Age groups}

The physician significantly underestimated the pain compared with the assessments by both the child and his/her parents. In children of 3-8 years of age, the physician estimated the mean pain level to be $\mathrm{NRS}=3.2$ lower than the child and $\mathrm{NRS}=1.8$ lower than the parent. In children of 9-15 years of age, the physician estimated the mean pain level to be NRS $=2.0$ lower than the child and NRS=1.5 lower than the parent (table 3). The difference in pain intensity ratings was significantly higher in the youngest compared with the oldest children, between both child-physician and child-parent.

\section{Diagnostic groups}

Physicians significantly underestimated the pain compared with both children and parents in all diagnostic groups, but less so in cases where fractures were involved. The mean pain level difference between the child and physician was significantly lower in children with fractures $(\mathrm{NRS}=1.2 ; 95 \%$ CI 0.5 to 2.0 ) comapred to children with wounds (NRS $=3.4 ; 95 \%$ CI 2.2 to $4.5 ; \mathrm{p}=0.001$ ), infections (NRS $=3.1 ; 95 \%$ CI 2.2 to 4.0 ; $\mathrm{p}=0.002$ ) and soft tissue injuries (NRS $=2.4 ; 95 \%$ CI 1.9 to $2.9 ; \mathrm{p}=0.007)($ table 3$)$.

Physicians' perception of concordance between medical condition and pain

The physicians were asked whether they found the child's pain reaction in concordance with the medical condition. When the concordance between the medical condition and the child's pain reaction was high, the mean difference in pain intensity ratings between the physician and child was significantly lower than when the concordance was low $(\mathrm{NRS}=2.0$ versus $\mathrm{NRS}=3.1)$ (table 3).

\section{Pain level}

The pain assessment between the child and physician significantly improved with increasing pain, as assessed by the physician. The mean difference in NRS was 3.2 (95\% CI 2.8 to 3.6 ; $\mathrm{p}<0.001)$ in children with mild pain, 1.2 (95\% CI 0.7 to 1.8 ; $\mathrm{p}<0.001)$ in children with moderate pain and $-0.6(95 \% \mathrm{CI}$ -1.7 to $0.6 ; \mathrm{p}=0.328$ ) in children with severe pain. Physicians sometimes recorded a higher NRS in children with severe pain (figure 2A). 


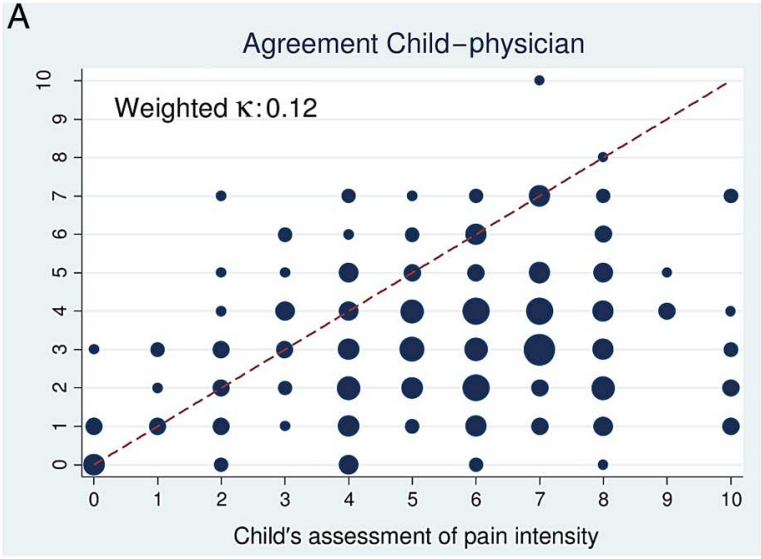

B

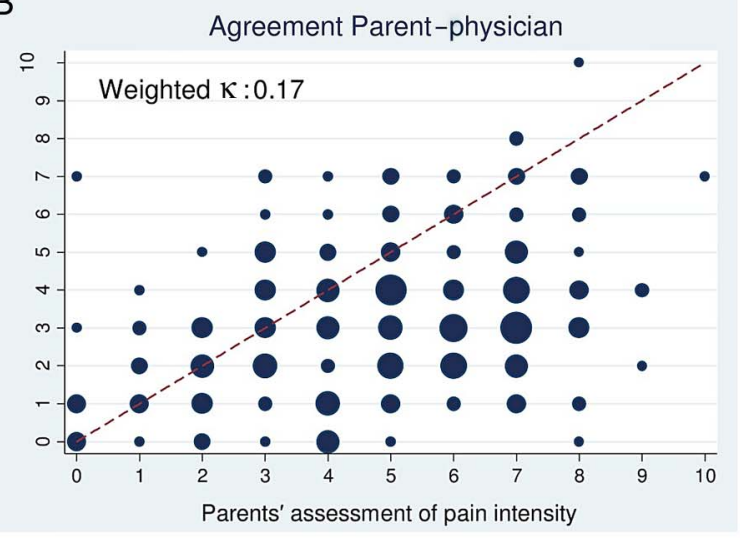

C

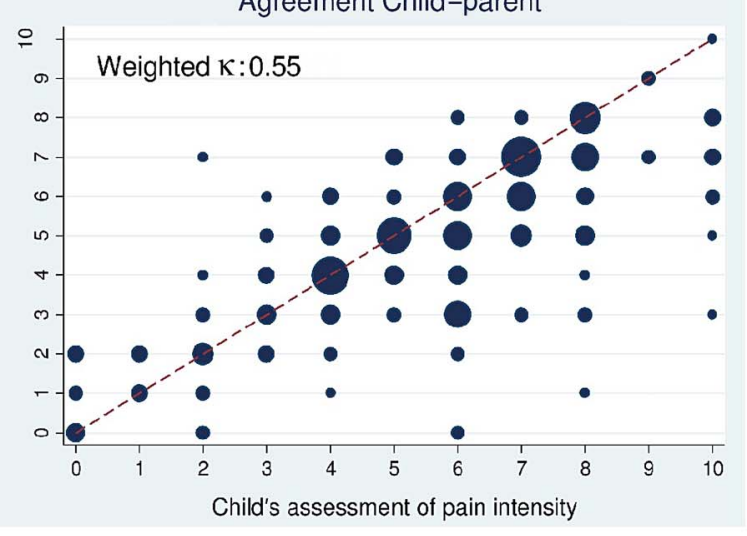

Figure 2 (A-C) Bubble charts illustrating the agreement in pain assessments between child-physician, parent-physician and childparent. The size of the bubbles refers to the number of patients.

\section{Physicians' administration of pain relief}

The doctors gave painkillers to $8.6 \%$ of the children at attendance (table 1). These children had a mean pain intensity of NRS $=4.9$ (SD 2.9), according to the physicians' assessments. Children who did not receive painkillers had a mean score of NRS $=2.9$ (SD 1.9). Physicians gave painkillers to $4.1 \%$ of 146 children with mild pain, $9.0 \%$ of 78 children with moderate pain and $42.1 \%$ of 19 children with severe pain, assessed by the physicians. When the pain grading was based on the child's pain assessment, only $14.3 \%$ of children with severe pain received painkillers. The exclusion of patients who got painkillers from their parents ahead of the consultation $(n=34)$ did not alter these findings.

\section{DISCUSSION}

Our main finding in this study is that ED physicians significantly underestimated children's pain. Previous studies have made similar observations, ${ }^{10}{ }^{11}$ but fortunately positive reports of improvements are registered in academic paediatric EDs. ${ }^{17}$

\section{Age groups and diagnostic groups}

Of special note in our study, and not previously addressed, is the detailed analysis of differences in pain assessments in relation to age groups and different diagnostic groups. Both parents and physicians underestimated pain in young children significantly more than in children older than 8 years. The pain scores in children with fractures corresponded well with their parents' pain assessments. Similarly, the mean difference in pain assessment for fractures between children and physicians was significantly lower than for other diagnostic categories. Fractures probably make pain more obvious, and might be the reason why parents, and to some extent physicians, seem to get closer to the child's own estimated pain level. Child fractures occur in almost $25 \%$ of all child injuries in need of medical attention at $\mathrm{EDs},{ }^{18}$ and pain is most severe within the first 48 hours after injury. Pain in infectious diseases may fluctuate and thus make pain assessments difficult and time dependent. This can explain why both parents and physicians underestimate this cause of pain. Still, prior to ED attendance, children with infections received more painkillers from their parents than children with other medical conditions. However, our study does not sufficiently address whether these painkillers were supposed to combat fever or pain.

\section{The complexity of pain perception and assessment}

The perception of pain is a complex phenomenon and a mix of somatic pain, anxiety and stress. ${ }^{24}$ It is a challenge for a parent or healthcare worker to estimate the pain intensity in the way they expect that the child would do, a so-called estimation by proxy. ${ }^{19}$ The adult must take the child's perspective and respond according to the child's own experience of the pain. The reliability of this varies and depends on the observer's attitudes, knowledge and the individual characteristics of the child. ${ }^{19}$ We found significant discrepancies in pain scores between the child and physician and also between the parent and physician. Parents seem to be better than physicians at assessing pain in their children. In a comparative analysis of the wellbeing of children with chronic neurological conditions, ${ }^{12}$ the child-parent conformity was better than the conformity between the child and physician. However, with increasing emotional distress and pain, both physicians and parents underestimated. ${ }^{12}$ It is likely that ED physicians' underestimation of children's pain is partly due to an unawareness of how much anxiety and stress exacerbate the child's perception of pain. Validated stress and anxiety scales exist for children older than 7 years, ${ }^{20}$ but their usefulness is controversial, especially since perceived pain and anxiety are so closely interconnected and difficult to distinguish in children. Not surprisingly, when the physicians in our study found the child's pain reaction disproportionate to the medical condition, the discrepancy in NRS assessments of pain increased between the child and physician. This gap was most likely due to the child's anxiety and stress. When health professionals identify a discrepancy in pain assessments and a negative correlation between the condition and the child's pain reaction, they should promptly make use of proven methods to reduce anxiety and stress. Age-appropriate explanations, establishing confidence, calmness and distractions are 
Table 3 Differences in mean pain intensity assessment between child-physician, parent-physician and child-parent by age groups, diagnostic groups and physicians' perceived degree of concordance between medical condition and pain $(\mathrm{N}=243)$

\begin{tabular}{|c|c|c|c|c|c|c|}
\hline \multirow[b]{2}{*}{ Characteristics } & \multicolumn{2}{|c|}{ Child-physician* } & \multicolumn{2}{|c|}{ Parent-physician* } & \multicolumn{2}{|c|}{ Child-parent } \\
\hline & Mean & $95 \% \mathrm{Cl}$ & Mean & $95 \% \mathrm{Cl}$ & Mean & $95 \% \mathrm{Cl}$ \\
\hline Total & 2.3 & 1.9 to 2.8 & 1.6 & 1.3 to 2.0 & 0.7 & 0.4 to 0.9 \\
\hline \multicolumn{7}{|l|}{ Age (years) } \\
\hline $3-8$ & 3.2 & 2.5 to 3.9 & 1.8 & 1.2 to 2.4 & 1.2 & 0.8 to 1.6 \\
\hline $9-15$ & 2.0 & 1.5 to 2.5 & 1.5 & 1.1 to 1.9 & 0.5 & 0.2 to 0.7 \\
\hline \multicolumn{7}{|l|}{ Diagnosis } \\
\hline Infection & 3.1 & 2.2 to 4.0 & 2.2 & 1.4 to 2.9 & 0.8 & 0.2 to 1.4 \\
\hline Wound & 3.4 & 2.2 to 4.5 & 2.0 & 1.0 to 2.9 & 1.1 & 0.3 to 1.8 \\
\hline Fracture & 1.2 & 0.5 to 2.0 & 0.8 & 0.2 to 1.5 & 0.5 & 0.1 to 1.0 \\
\hline Soft tissue, ligament or muscle injury & 2.4 & 1.9 to 2.9 & 1.7 & 1.3 to 2.2 & 0.6 & 0.3 to 0.9 \\
\hline \multicolumn{7}{|c|}{ Concordance between medical condition and pain } \\
\hline Low & 3.1 & 2.0 to 4.2 & 2.6 & 1.6 to 3.6 & 0.8 & 0.1 to 1.6 \\
\hline Some & 2.7 & 2.1 to 3.3 & 1.9 & 1.4 to 2.4 & 0.7 & 0.3 to 1.1 \\
\hline High & 2.0 & 1.5 to 2.5 & 1.3 & 0.8 to 1.7 & 0.6 & 0.3 to 1.0 \\
\hline
\end{tabular}

useful and effective examples. ${ }^{4}$ Still, sufficient pain relief is essential in order to be able to use these other methods fully.

\section{Pain levels}

In a former ED study of children with acute conditions, the discrepancy in pain assessments by the child and parent increased with increasing pain scores. ${ }^{21}$ Fortunately, we found the opposite. The agreement in assessments between both the childparent and child-physician increased with increasing levels of pain. Sometimes, physicians even assessed the child's pain to be higher than the child's own assessment. The clinical significance of poor physician-patient pain concordance for mild pain may not be critical, even with a mean discrepancy of $\mathrm{NRS}=3.1$. A study of back pain has previously shown that the difference in pain needs to be $\mathrm{NRS} \geq 2$ in order to be clinically meaningful and exceed the bounds of measurement errors. ${ }^{22}$ This implies that some children in the mild pain category might have moderate pain. Despite this, the trend of improved concordance with increasing pain is reassuring and of clinical importance in both diagnostics and treatment.

\section{Pain relief}

According to ethical aspects and a human rights perspective, the gold standard is that pain relief should be based on the child's own experience of the pain. ${ }^{14}$ It is also recommended that pain relief should be administered for postoperative pain when VAS $>3 .{ }^{4}$ Our physicians provided painkillers to children with a mean pain score of 4.9. Fortunately, the percentage of children receiving painkillers increased with increasing levels of pain. Still, only $42.1 \%$ of children with severe pain (NRS $\geq 7$ ), assessed by the physicians, received analgesics. Based on the child's pain assessment, only $14.3 \%$ of children with severe pain received pain relief.

\section{Limitations}

Our study has some limitations that must be considered. Young children's ability to understand and use the pain severity tools correctly, despite instructions, could be questioned. However, several validity studies underline that children are competent at this from the age of 3 to 4 years. ${ }^{14}$ In our study, children in the two age groups used different pain severity scales, and the children used different scales than physicians and parents. Validity studies have shown that discrepancies exist between different pain scales ${ }^{15}$ and this might have influenced the reliability of comparing pain estimations. However, parents and physicians used the same NRS in our study, and yet they had significantly different evaluations of the child's pain.

\section{CONCLUSION}

ED physicians significantly underestimated pain in all paediatric patients $\geq 3$ years old. This applied to all categories of medical conditions, but less so in children with fractures. When the physician experienced a low concordance between the child's perceived pain and the medical condition, the child-physician discrepancy increased. In these situations, it seems important to address the child's anxiety and stress in addition to provide general pain relief. Even parents underestimated the pain, but their assessments were closer to the child's experienced pain. This implies that in the absence of a self-report from the child, physicians should listen to parents' evaluations. It seems contradictory that, despite improved assessments with increasing pain, less than half of the children with severe pain received analgesics in ED. Further research should look into the reasons why treatment of moderate and severe pain, identified by the physician, remains inadequate.

Acknowledgements The authors would like to thank the physicians and other health workers who participated in the study at Bergen Accident and Emergency Department.

Contributors S-DM, CB and TM conceived and designed the study. S-DM, CB and TM acquired data. $C B, V B$, TM and S-DM analysed and interpreted the data. $C B$ drafted the article. VB and TM revised it critically for important intellectual content. $C B, V B, S-D M$ and TM approved the final version to be submitted. CB, S-DM, VB and TM were responsible for the overall content as guarantors.

Funding Financial support was provided by the National Centre for Emergency Primary Health Care, Uni Research Health, Bergen, Norway, Norwegian Medical Association's Funds for Research in General Practice, Medicines for Children Network at Haukeland University Hospital, Bergen, and Norwegian Association for Pain in Childhood.

Competing interests None declared.

Patient consent Parental/guardian consent obtained.

Ethics approval The Norwegian Ethical Committee for Medical Research.

Provenance and peer review Not commissioned; externally peer reviewed.

Open Access This is an Open Access article distributed in accordance with the Creative Commons Attribution Non Commercial (CC BY-NC 4.0) license, which permits others to distribute, remix, adapt, build upon this work non-commercially, and license their derivative works on different terms, provided the original work is 
properly cited and the use is non-commercial. See: http://creativecommons.org/ licenses/by-nc/4.0/

\section{REFERENCES}

1 Krauss BS, Calligaris L, Green SM, et al. Current concepts in management of pain in children in the emergency department. Lancet 2016;387:83-92.

2 Anand KJ, Carr DB. The neuroanatomy, neurophysiology, and neurochemistry of pain, stress, and analgesia in newborns and children. Pediatr Clin North Am 1989;36:795-822.

3 Brennan F, Carr DB, Cousins M. Pain management: a fundamental human right. Anesth Analg 2007;105:205-21.

4 Fein JA, Zempsky WT, Cravero JP, Committee on Pediatric Emergency Medicine and Section on Anesthesiology and Pain Medicine; American Academy of Pediatrics. Relief of pain and anxiety in pediatric patients in emergency medical systems. Pediatrics 2012;130:e1391-405.

5 Walco GA, Cassidy RC, Schechter NL. Pain, hurt, and harm. The ethics of pain control in infants and children. N Engl J Med 1994;331:541-4.

6 Grunau R. Long-term effects of pain in children. In: McGrath PJ, Stevens BJ, Walker SM, et al, eds. Oxford textbook of paediatric pain. Oxford: Oxford University Press, 2013:30-8.

7 Weisman SJ, Bernstein B, Schechter NL. Consequences of inadequate analgesia during painful procedures in children. Arch Pediatr Adolesc Med 1998;152:147-9.

8 Grant PS. Analgesia delivery in the ED. Am J Emerg Med 2006;24:806-9.

9 Brown JC, Klein EJ, Lewis CW, et al. Emergency department analgesia for fracture pain. Ann Emerg Med 2003;42:197-205.

10 Rajasagaram U, Taylor DM, Braitberg G, et al. Paediatric pain assessment: differences between triage nurse, child and parent. J Paediatr Child Health 2009;45:199-203.
11 Singer AJ, Gulla J, Thode HC Jr. Parents and practitioners are poor judges of young children's pain severity. Acad Emerg Med 2002;9:609-12.

12 Morrow AM, Hayen A, Quine S, et al. A comparison of doctors', parents' and children's reports of health states and health-related quality of life in children with chronic conditions. Child Care Health Dev 2012;38:186-95.

13 Moutte SD, Brudvik C, Morken T. Physicians' use of pain scale and treatment procedures among children and youth in emergency primary care-a cross sectional study. BMC Emerg Med 2015;15:33

14 Stinson JN, Kavanagh T, Yamada J, et al. Systematic review of the psychometric properties, interpretability and feasibility of self-report pain intensity measures for use in clinical trials in children and adolescents. Pain 2006;125:143-57.

15 Hjermstad MJ, Fayers PM, Haugen DF, et al. European Palliative Care Research Collaborative (EPCRC). Studies comparing Numerical Rating Scales, Verbal Rating Scales, and Visual Analogue Scales for assessment of pain intensity in adults: a systematic literature review. J Pain Symptom Manage 2011;41:1073-93.

16 Landis JR, Koch GG. The measurement of observer agreement for categorical data. Biometrics 1977;33:159-74.

17 Bhargava R, Young KD. Procedural pain management patterns in academic pediatric emergency departments. Acad Emerg Med 2007;14:479-82.

18 Brudvik C. Child injuries in Bergen, Norway. Injury 2000;31:761-7.

19 Craig KD, Versloot J, Goubert L, et al. Perceiving pain in others: automatic and controlled mechanisms. J Pain 2010;11:101-8.

20 Alfvén $\mathrm{G}$, Nilsson $\mathrm{S}$. Validity and reliability of a new short verbal rating scale for stress for use in clinical practice. Acta Paediatr 2014;103:e173-5.

21 Kelly AM, Powell CV, Williams A. Parent visual analogue scale ratings of children's pain do not reliably reflect pain reported by child. Pediatr Emerg Care 2002;18:159-62.

22 Childs JD, Piva SR, Fritz JM. Responsiveness of the numeric pain rating scale in patients with low back pain. Spine 2005;30:1331-4. 